\title{
Quality of life index in autoimmune bullous dermatosis patients ${ }^{*}$
}

\author{
Mariana Álvares Penha ${ }^{1}$ \\ Hélio Amante Miot ${ }^{1}$ \\ DOI: http://dx.doi.org/10.1590/abd1806-4841.20153372
}

Joyce Godoy Farat ${ }^{1}$

Sílvia Regina Catharino Sartori Barraviera ${ }^{1}$

\begin{abstract}
BACKGROUND: Autoimmune bullous dermatoses are complex diseases triggered by autoantibodies action against epidermal antigens or the dermoepidermal junction. Blisters and vesicles that evolve with erosion areas characterize them. Although rare, they present high morbidity, affecting the quality of life of patients.

OBjeCtives: To assess the magnitude of autoimmune bullous dermatoses on life quality of patients treated in a public university service in countryside of Brazil.

METHODS: This cross-sectional study was based on an inquiry with autoimmune bullous dermatoses patients assisted at outpatient university referral service. Elements related to quality of life were evaluated by the Dermatology Life Quality Index, as well as clinical and demographic data.

RESULTS: The study evaluated 43 patients with pemphigus foliaceus, 32 with pemphigus vulgaris, 6 with bullous pemphigoid and 3 with dermatitis herpetiformis. The average age was $48 \pm 16$ years and 34 (40\%) were female. The median score (p25-p75) of the Dermatology Life Quality Index was 16 (9-19), classified as "severe impairment" of life quality, in which the greater impact was related to symptoms and feelings, daily and leisure activities.

CONCLUSIONS: Autoimmune bullous dermatoses inflict severe impairment of quality of life for patients followed by a public outpatient clinic in the countryside of Brazil.
\end{abstract}

Keywords: Dermatitis herpetiformis; Pemphigoid, bullous; Pemphigus; Quality of life; Skin diseases, vesiculobullous

\section{INTRODUCTION}

Autoimmune bullous dermatoses (ABD) are complex diseases triggered by autoantibodies action against epidermal antigens or dermoepidermal junction. Their clinical severity varies from formes frustes, with spontaneous remission, to lethal forms refractory to treatment. They are characterized by vesicules and cutaneous blisters which evolve with erosion areas. The classification depends on the site of the blister in the epithelium, which may be subepidermal and intraepidermal, besides the pathological substrate (e.g. location of acantholysis). ${ }^{1}$

The main $\mathrm{ABD}$ are pemphigus vulgaris $(\mathrm{PV})$, pemphigus foliaceus (PF), bullous pemphigoid (BP) and dermatitis herpetiformis (DH), low incidence entities (1.9 - 4.3 cases for every 100,000 adults) of high morbidity, which significantly compromise the quality of life (QOL) of patients. ${ }^{2-5}$
There are few reports in literature about the impact of clinical symptoms of ABD in the quality of life of patients, and these are frequently underestimated by clinicians. ${ }^{6}$

The Dermatology Life Quality Index (DLQI), developed by Finlay and Khan in 1994, was the first tool of QOL evaluation related to dermatology. ${ }^{7}$ It consists of ten items, which estimate disease influence regarding: symptoms and feelings, daily activities, leisure, work, school, personal relationships and treatment. It has already been translated and validated into Brazilian Portuguese and applied to several dermatoses (DLQI-BRA) (Chart 1). . $^{8-11}$

The impressions as to the impact of the disease on the life of patients are fundamented by cultural and ethnic aspects, which justifies the evaluation of QOL in different population groups. There are few

\footnotetext{
Received on 13.01.2013.

Approved by the Advisory Board and accepted for publication on 16.03.2014

* Work performed at Departamento de Dermatologia e Radioterapia da Faculdade de Medicina - Universidade Estadual Paulista "Júlio de Mesquita Filho" - (Unesp)

- Botucatu (SP), Brazil.

Conflict of interest: None

Financial funding: None

Universidade Estadual Paulista "Júlio de Mesquita Filho" - (Unesp) - Botucatu (SP), Brazil.
} 
ChART 1: DLQI-BRA (Dermatology Life Quality Index). Items and dimensions evaluated by the validated construct for the Portuguese language

\begin{tabular}{|c|c|}
\hline Items / Questions* & Latent dimensions \\
\hline $\begin{array}{l}\text { 1. How much was your skin } \\
\text { affected during last week due } \\
\text { to itching, inflammation, } \\
\text { pain or burning? }\end{array}$ & $\begin{array}{l}\text { Symptoms } \\
\text { and feelings }\end{array}$ \\
\hline $\begin{array}{l}\text { 2. How much embarrassment or } \\
\text { other kind of limitation was caused } \\
\text { by your skin during last week? }\end{array}$ & \\
\hline $\begin{array}{l}\text { 3. How much did your skin } \\
\text { interfere with your activities of } \\
\text { shopping or rides, at home or } \\
\text { public places, during last week? }\end{array}$ & Daily activities \\
\hline $\begin{array}{l}\text { 4. Up to what point did your skin } \\
\text { interfere with the clothes you } \\
\text { normally use during last week? }\end{array}$ & \\
\hline $\begin{array}{l}\text { 5. How much did your skin affect } \\
\text { one of your social or leisure } \\
\text { activities last week? }\end{array}$ & Leisure \\
\hline $\begin{array}{l}\text { 6. How hard was it for you to } \\
\text { practice sports during } \\
\text { last week? }\end{array}$ & \\
\hline $\begin{array}{l}\text { 7. Did your skin prevent you from } \\
\text { working or studying } \\
\text { during last week?** }\end{array}$ & Work and school \\
\hline $\begin{array}{l}\text { 8. How problematic has your } \\
\text { relationship become with your } \\
\text { partner, close friends or relatives, } \\
\text { because of your skin? }\end{array}$ & Relationships \\
\hline $\begin{array}{l}\text { 9. Up to what point did your skin } \\
\text { present difficulties for your } \\
\text { sexual life last week? }\end{array}$ & \\
\hline $\begin{array}{l}\text { 10. Up to what point did your } \\
\text { dermatological treatment present } \\
\text { problems for you last week? }\end{array}$ & Treatment \\
\hline \multicolumn{2}{|c|}{$\begin{array}{l}\text { DLQI, Dermatology Life Quality Index; *Admits as answers: } \\
3 \text { (too much), } 2 \text { (a lot), } 1 \text { (a little), } 0 \text { (nothing or irrelevant); } \\
\text { **Accepts: } 3 \text { (too much) or } 0 \text { (nothing or irrelevant). } \\
\text { In case of negative, it asks: Has your skin been a problem } \\
\text { for you at work or at school? Accepting: } 2 \text { (a lot) or } 0 \\
\text { (nothing or irrelevant). }\end{array}$} \\
\hline
\end{tabular}

studies on QOL in ABD of Latin-American populations.

The goal of this work was to evaluate the impact of autoimmune bullous dermatoses on the
QOL of patients treated in a university service in Botucatu-SP (Brazil).

\section{METHODS}

A cross-sectional study was conducted in which a survey was performed regarding the impact on QOL caused by ABDs through the DLQI-BRA questionnaire. ${ }^{8} \mathrm{ABD}$ carrying patients were included and interviewed during their medical appointments at the bullous diseases outpatient clinic of School of Medicine Unesp (Faculdade de Medicina - Unesp) (Botucatu$\mathrm{SP})$, between the months of February and December of 2012. The project was approved by the Research Ethics Committee of the institution (no. 4137/2012) and all patients signed the informed consent form before the interview.

Demographical, clinical and QOL related data were investigated. The total score of DLQI was computed from the sum of indexes of the ten items evaluated and interpreted as: no impairment on life quality $(0-1)$ or with light (2-5), moderate (6-10), severe (11-20) or very severe (21-30) impairment. ${ }^{7}$

Categorical data were represented by their absolute frequencies and percentages, and compared by the chi-square test. Continuous data were represented by averages and standard deviations, or median and interquartile range, and the groups had medians compared by the Kruskal-Wallis test. Normality was assessed by Lilliefors test and homoscedasticity by Levene's test. The internal consistency of the questionnaire was estimated by Cronbach's alpha coefficient. The behavior of scores of items was evaluated regarding the similarity by evaluating clusters (cluster analysis - between items linkage). ${ }^{12}$

An analysis of total scores and of independent dimensions was later performed according to subgroups: gender, age, literacy and duration of disease. Data was adjusted by the generalized linear model (ANCOVA) and all covariates included.

Results were tabulated with MS Excel 2003 and analyzed by IBM SPSS 20.0 software. Value of $p<0.05$ was considered significant.

\section{RESULTS}

84 patients with bullous diseases were interviewed. There was no exclusion of patients, and all agreed to take part in the study.

The main clinical and demographical data are shown in table 1. Highlights are the greater frequency of pemphiguses, long duration of diseases and DLQI graded as "severe impairment of life quality".

Cronbach's alpha coefficient resulted in 0.81, assuring internal consistency of the questionnaire.

The scores of the different dimensions evaluated by the DLQI questionnaire are laid out on figure 1 . 
The greater impact on quality of life of items related to symptoms and feelings, daily activities and leisure stands out.

Clusters of items with behaviors of similar scores are shown in figure 2.

The medians (p25-p75) of total DLQI scores of patients with pemphigus vulgaris, pemphigus foliaceus or bullous pemphigoid / dermatitis herpetiformis did not significantly differ from each other (16 $(10-19) \times 17(13-20) \times 11$ (5-20); $\mathrm{p}=0.34)$.

When evaluated in a multivariate manner (ANCOVA), higher total scores of DLQI were associated with female gender and shorter schooling (Table 2).

TABLE 1: Clinical and demographical data of interviewed patients with $\mathrm{ABD}$

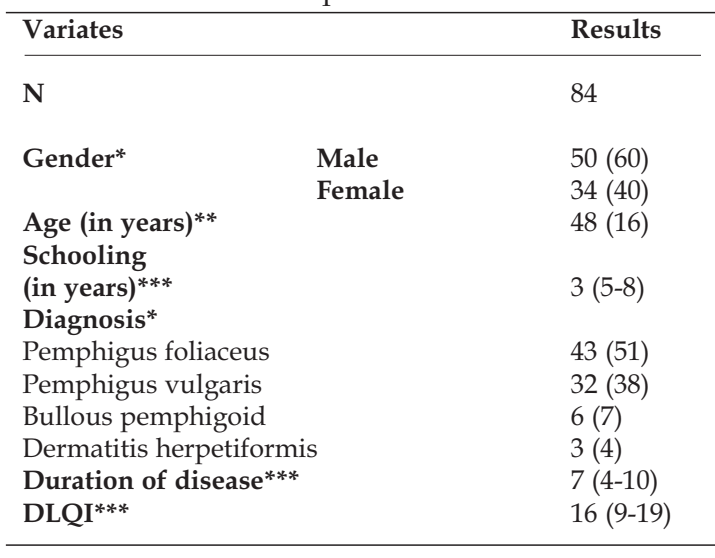

${ }^{*} \mathrm{~N}(\%),{ }^{* *}$ average (standard deviation); ${ }^{* * *}$ median (p25-p75).

\section{DISCUSSION}

ABDs are chronic diseases, rare, however with great impairment of QOL of patients. The symptoms, clinical forms and also the effects of treatment contribute for a greater morbidity.

ABDs present several clinical presentations with mucosal involvement, and/or a great extension of the tegument. Even though it presents a decreasing rate of mortality due to the development of adjuvant treatments of the disease, all ABD subtypes have a restrict prognosis, $\mathrm{PV}$ being the worst of them. ${ }^{13}$

The DLQI score was high (16), revealing that the impact of QOL is larger than other chronic dermatological diseases such as: urticaria (14), leprosy (11), psoriasis, (10), basal cell carcinoma (9), atopic dermatitis (8), among others. ${ }^{9,14-17}$ Mayrshofer and colleagues also showed a higher DLQI score than other dermatoses in patients with PV. ${ }^{18}$

The impact measured was greater in women and people with few years of schooling. Paradisi et al reported, likewise, greater QOL involvement in the female gender, showing that women express greater suffering and fragility regarding ABDs. ${ }^{19}$

Paradisi and colleagues emphasize that QOL depends on the treatment and collateral effects caused by it, concluding that most deaths occur from complications arising from the treatment employed, triggering low compliance with medical recommendations. ${ }^{20}$ It also pointed out that multiple comorbidities influence negatively the QOL of patients, showing a more important relation in patients with bullous dermatoses associated with psychiatric disorders, which

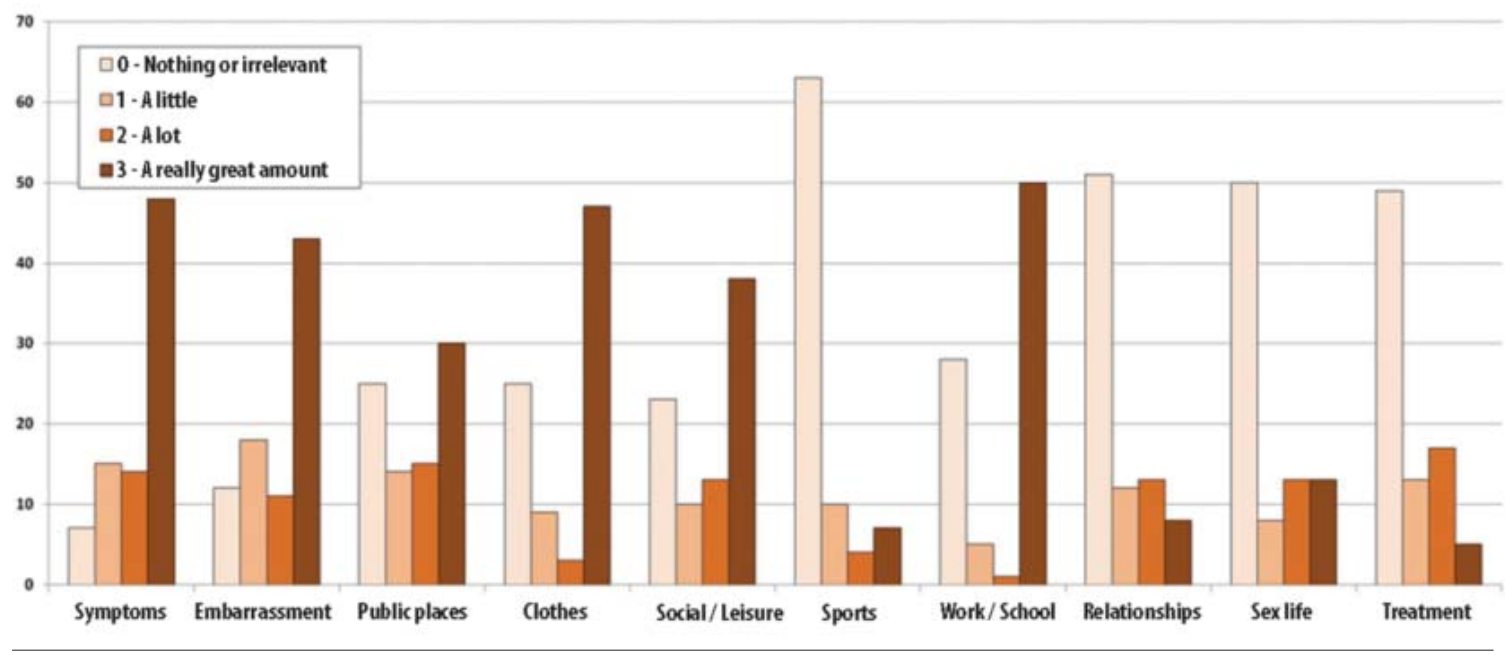

FIGURE 1: Scores of DLQI-BRA items for patients with ABD 


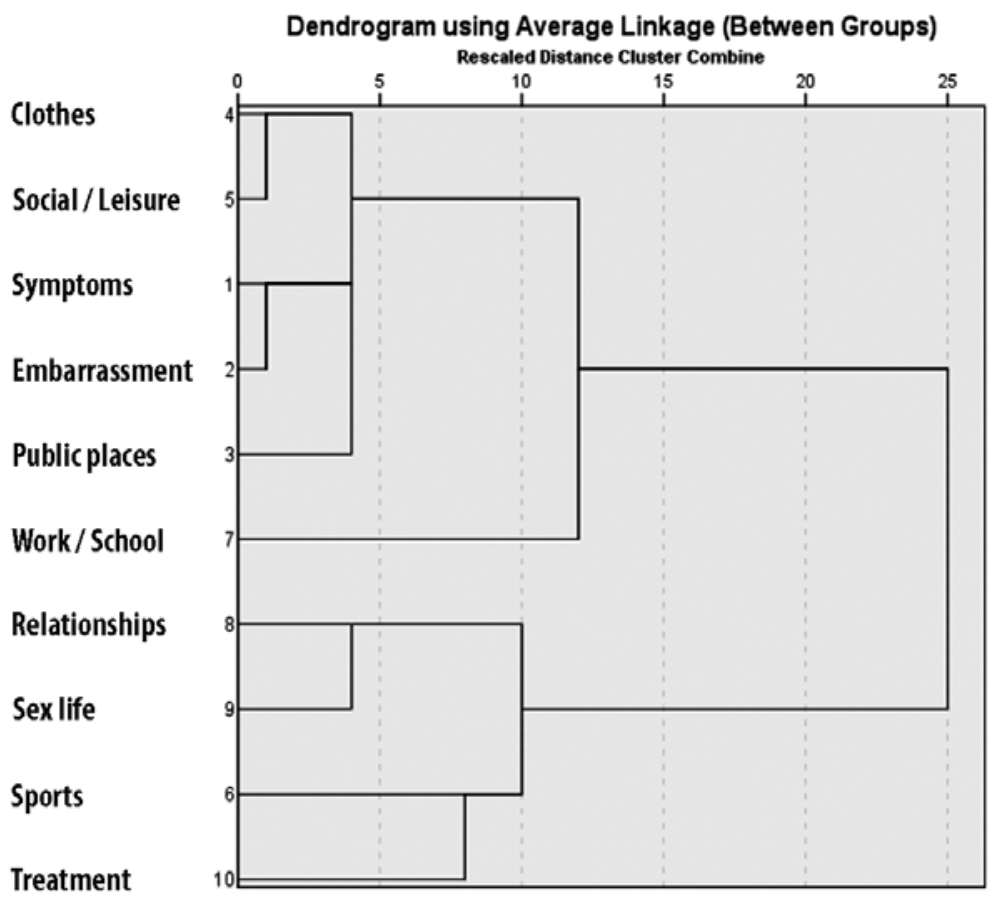

Figure 2: Dendrogram using behavior of scores of items that compose DLQI

TABLE 2: Multivariate analysis (ANCOVA) of total score of DLQI according to clinical-demographic variables

\begin{tabular}{|c|c|c|}
\hline Variable & Coeficient $\beta$ & p-value \\
\hline Age & 0.03 & 0.96 \\
\hline \multicolumn{3}{|l|}{ Diagnosis } \\
\hline PV & 1.00 & \\
\hline PF & 0.70 & \\
\hline $\mathrm{BP} / \mathrm{DH}$ & -2.40 & 0.63 \\
\hline Years of schooling & -0.56 & 0.02 \\
\hline Duration of disease & 0.06 & 0.43 \\
\hline Female gender & 3.35 & 0.03 \\
\hline
\end{tabular}

$\mathrm{p}$ (model) $<0.05 ; \mathrm{p}$ (interception) $<0.01$

presented lower QOL scores compared to those without psychiatric diseases.

The limitations of this study are based mainly on the evaluation by a single university center and by little sample representation of patients with bullous pemphigoid or dermatitis herpetiformis. However, they did not prevent perceiving the global impact that the ABD inflict on QOL of patients and positioning them among dermatoses of greater morbidity, besides being the first Brazilian investigation about QOL regarding $\mathrm{ABDs}$.

\section{CONCLUSION}

Autoimmune bullous diseases inflict severe impairment to the quality of life of patients from a public outpatient clinic in the countryside of Brazil. Early precise diagnosis and therapeutic intervention aim to reduce the impact of QOL inflicted by ABD. 


\section{REFERENCES}

1. Maruta CW, Santi CG, Rivitti EA, Sampaio SA. Erupções Vésico-Bolhosas. In: Sampaio SA, Rivitti, EA. Dermatologia. 3 ed. São Paulo: Artes Médicas; 2007. p. 301-30.

2. Schmidt $E$, Zillikens $D$. The diagnosis and treatment of autoimmune blistering skin diseases. Dtsch Arztebl Int. 2011;108:399-405.

3. Bertram F, Bröcker EB, Zillikens D, Schmidt E. Prospective analysis of the incidence of autoimmune bullous disorders in Lower Franconia, Germany. J Dtsch Dermatol Ges. 2009;7:434-40.

4. Langan SM, Smeeth L, Hubbard R, Fleming KM, Smith CJ, West J. Bullous pemphigoid and pemphigus vulgaris-incidence and mortality in the UK: population based cohort study. BMJ. 2008;337:a180.

5. Cunha PR, Barraviera SRCS. Autoimmune bullous dermatoses. An Bras Dermatol. 2009;84:111-24.

6. Sebaratnam DF, McMillan JR, Werth VP, Murrell DF. Quality of life in patients with bullous dermatoses. Clin Dermatol. 2012;30:103-7.

7. Finlay AY, Khan GK. Dermatology Life Quality Index (DLQI) - a simple practical measure for routine clinical use. Clin Exp Dermatol. 1994;19:210-6.

8. Dermatology.org. [Internet]. Dermatology Life Quality Index (DLQI) Different languages versions. [cited 2014 Jan 31]. Available from: http://www.dermatology.org.uk/downloads/dlqiportuguesebraz.doc

9. Silvares MRC, Fortes MRP, Miot HA. Quality of life in chronic urticaria: a survey at a public university outpatient clinic, Botucatu (Brazil). Rev Assoc Med Bras. 2011;57:577-82.

10. Nijsten T, Meads DM, McKenna SP. Dimensionality of the dermatology life quality index (DLQI): a commentary. Acta Derm Venereol. 2006;86:284-5.

11. Ghodsi SZ, Chams-Davatchi C, Daneshpazhooh M, Valikhani M, Esmaili N. Quality of life and psychological status of patients with pemphigus vulgaris using Dermatology Life Quality Index and General Health Questionnaires. J Dermatol. 2012;39:141-4.

12. Norman GR, Streiner DL. Biostatistics. The bare essentials. 3rd ed. Shelton, Connecticut: People's Medical Publishing House; 2008.

13. Souza SR, Azulay-Abulafia L, Nascimento LV. Validation of the commitment index of skin and mucous membranes in pemphigus vulgaris for the clinical evaluation of patients with pemphigus vulgaris. An Bras Dermatol. 2011;86:284-91.

14. Silva MF, Fortes MR, Miot LD, Marques SA. Psoriasis: correlation between clinical severity (PASI) and quality of life index (DLQI) in patients assessed before and after systemic treatment. An Bras Dermatol. 2013;88:760-3.

15. Ludwig MW, Oliveira Mda S, Muller MC, Moraes JF. Quality of life and site of the lesion in dermatological patients. An Bras Dermatol. 2009;84:143-50.

16. Taborda ML, Weber MB, Teixeira KA, Lisboa AP, Welter Ede Q. Evaluation of the quality of life and psychological distress of patients with different dermatoses in a dermatology referral center in southern Brazil. An Bras Dermatol. 2010;85:52-6.
17. Martins GA, Arruda L, Mugnaini ASB. Validation of life quality questionnaires for psoriasis patients. An Bras Dermatol. 2004;79:521-35.

18. Mayrshofer F, Hertl M, Sinkgraven R, Sticherling M, Pfeiffer C, Zillikens D, et al. Significant decrease in quality of life in patients with pemphigus vulgaris. Results from the German Bullous Skin Disease (BSD) Study Group. J Dtsch Dermatol Ges. 2005;3:431-5.

19. Paradisi A, Sampogna F, Di Pietro C, Cianchini G, Didona B, Ferri R, et al. Quality-oflife assessment in patients with pemphigus using a minimum set of evaluation tools. J Am Acad Dermatol. 2009;60:261-9.

20. Paradisi A, Cianchini G, Lupi F, Di Pietro C, Sampogna F, Didona B, et al. Quality of life in patients with pemphigus receiving adjuvant therapy. Clin Exp Dermatol. 2012;37:626-30

MAILING ADDRESS:

Sílvia R. C. S. Barraviera.

Departamento de Dermatologia e Radioterapia da FMBUnesp, SN,

Campus Universitário de Rubião Jr.

18618-000 - Botucatu - SP

Brazil

E-mail: dermato@fmb.unesp.br

How to cite this article: Penha MA, Farat JG, Miot HA, Barraviera SRCS Quality of life index in autoimmune bullous dermatosis patients. An Bras Dermatol. 2015;90(2):190-4. 